\title{
EL PAPEL DE LAS MUJERES EN LA HISTORIA SEGÚN LAS IMÁGENES DE LOS LIBROS DE TEXTO. COMPARACIÓN DE MANUALES EDITADOS DURANTE LA LOE Y LA LOMCE
}

\section{The role of women in bistory according to textbooks images. Comparison of textbooks published during $L O E$ and LOMCE}

\author{
Juan Carlos BeL Martínez \\ Universitat de València \\ Correo-e: belmartinezjc@gmail.com \\ Recepción: 2 de septiembre de 2015 \\ Envío a informantes: 27 de octubre de 2015 \\ Aceptación definitiva: I2 de enero de 2016
}

Resumen: Este trabajo se centra en el estudio del papel de las mujeres y su representación en las imágenes de los libros de texto de Conocimiento del Medio y Ciencias Sociales, concretamente en las unidades de Historia. Los manuales educativos pueden aportar una visión global de la forma en que se presenta a las mujeres en el discurso histórico transmitido desde la Educación Primaria, y mediante su análisis podemos ver si este tiene o no un sesgo androcéntrico. A partir de ello se desarrolla un análisis y comparación de los datos obtenidos entre ejemplares de las dos últimas reformas educativas implementadas en España (LOE y LOMCE).

Palabras clave: mujeres; Historia; libros de texto; imágenes; coeducación.

Aвstract: This paper focuses on the study of the role of women and its representation in the images of the textbooks of Environmental Knowledge and Social Sciences subjects, specifically in History topics. Textbooks can give us an overview of how women are presented in the historical discourse carried from Primary Education, and

Este artículo parte de un Trabajo de Final de Grado realizado en la Universitat Jaume I que fue tutorizado por el profesor Enric Ramiro Roca, del Departamento de Educación. Queremos agradecer al profesor Ramiro la dirección del trabajo y toda la ayuda prestada, así como a los profesores de la Universitat de València Xosé Manuel Souto González y Rafael Valls Montés por sus aportaciones. 
EL PAPEL DE LAS MUJERES EN LA HISTORIA SEGÚN LAS IMÁGENES DE LOS LIBROS DE TEXTO. COMPARACIÓN DE MANUALES EDITADOS DURANTE LA LOE Y LA LOMCE JUAN CARLOS BEL MARTÍNEZ

through their analysis we can see if it has or not an androcentric bias. Therefrom it's developed an analysis and a comparison of the data between volumes of both last education laws implemented in Spain (LOE and LOMCE).

KEY wORDs: women; History; textbooks; images; co-education.

\section{Introducción}

$\mathrm{D}$

URANTE LA FORMACIÓN DE LOS INDIVIDUOS y la construcción de sus personalidades, tienen un gran peso los valores colectivos compartidos a nivel social. En nuestro caso, la cultura androcéntrica en la que nos encontramos inmersos promueve la supremacía de los valores de dominación masculina por encima de otros valores y otorga a uno y otro sexo unos determinados roles culturales y sociales. Por ello podemos deducir que la escuela, en su papel de institución socializadora, ha transmitido y continúa transmitiendo en muchos casos esta visión androcéntrica sobre el mundo y las personas (Lomas, 2002: 197).

En este proceso socializador que encabezan las instituciones educativas poseen una gran influencia los materiales didácticos, especialmente los libros de texto por continuar siendo los más utilizados en nuestras aulas (Blanco, 200ob; Lomas, 2002; Ruiz y Vallejo, 1999) y por el carácter simbólico que han adquirido en el último siglo (Choppin, 2000: I4). Los libros de texto se caracterizan por contener las reglas morales de la ideología dominante (Choppin, 2000: I6; Morales y Lischinsky, 2008: I24; Ruiz y Vallejo, I999: 137), y al mismo tiempo se autolegitiman social y científicamente como portadores de la representación global y unitaria de la realidad (Blanco, 2ooob: I20; Valls, 2007a: 207).

A esto hay que sumar todos aquellos modelos y conocimientos no explícitos que transmiten los manuales por medio del currículum oculto y que el alumnado asume de forma automática al considerarlos como «naturales». Según señala Martín (2006: 8I), cuando estos modelos se proponen de forma no explícita y contienen rasgos propios de una ideología sexista, son aceptados de forma irresistible por niñas y niños, principalmente si son planteados como indiscutibles y tan evidentes que no necesitan ni ser formulados.

Por otra parte, debemos tener en cuenta que cuando un niño o una niña se aproxima a un libro aquello que primero capta su atención son las ilustraciones (Terrón y Cobano, 2008: 388), sobre todo por su colorido y por la capacidad del lenguaje simbólico de transmitir mucha información de forma sintética. Partiendo de este principio y del demostrado impacto positivo que tienen las imágenes en el aprendizaje (Ruiz y Vallejo, I999: I26), su inclusión en los libros de texto es incuestionable, pero no podemos olvidar el gran poder que tienen para afianzar en la memoria los estigmas sociales (Casablancas, 200I: I7). Paralelamente a esto, hay que señalar que existen estudios recientes como el de Valls (2007b) o el de Sáiz (20II) que indican que los libros de texto de historia hacen cada vez un mayor uso de las imágenes, y que estas son los elementos de los manuales que más han variado en los últimos años (Valls, 2007a). No obstante, y aunque aquí nos centremos en los recursos icónicos, creemos que tanto el texto como las actividades también deben ser considerados a la hora de evaluar de forma más completa los roles culturales y sociales 
transmitidos por los libros, entre otras cosas, por los modelos de identificación de género que presenten.

En lo que se refiere al marco legislativo que regula la igualdad de mujeres y hombres en manuales educativos, hay que destacar que en las últimas reformas educativas ha habido cambios al respecto. De este modo, mientras que en la LOE $^{2}$ se reconocía el deber de los libros de texto de respetar la igualdad de género, en la $\mathrm{LOMCE}^{3}$ no aparece dicha norma ni ninguna similar. A pesar de ello, la legislación autonómica de cada comunidad sí contempla este tipo de requisitos, como es el caso del Decreto II9/20I5 de la Generalitat de Catalunya ${ }^{4}$ que hace referencia a la no discriminación de los manuales por motivos de nacimiento, raza, sexo, opinión o cualquier otra condición o circunstancia personal o social; o el Decreto 32/20I4 de I8 de julio del Govern de les Illes Balears 5 , que también considera unos puntos similares a estos.

En este caso, los libros de texto que nos disponemos a analizar están regulados bajo el Decreto ro8/20r4 de la Comunitat Valenciana ${ }^{6}$, que en el momento de definir los rasgos generales de este material reconoce su obligación de respetar la igualdad de género.

\section{Marco teórico}

\section{I. Los manuales como objeto de estudio}

En nuestro país, los libros de texto han sido materia de análisis para la investigación educativa desde hace más de cuatro décadas. En este tiempo uno de los hitos que más influencia ha tenido fue la creación en 1992 del proyecto MANES, cuyos principales objetivos son catalogar y estudiar los manuales españoles de los últimos dos siglos (Tiana, 2000: I8I). En cuanto a los tipos de investigaciones que se han llevado a cabo encontramos que, mientras que algunos estudios se han centrado en evaluar su valor didáctico mediante el análisis del discurso, de las ilustraciones y de las actividades (Prendes, I997; Sáiz, 20II), otros se han decantado por indagar en las convenciones sociales que difunden de forma tácita (Bernete, I994; Moreno, 1986).

Centrándonos en este segundo grupo, cabe destacar los trabajos que han abordado el tema del sexismo en los manuales escolares. En España, el mayor número de investigaciones sobre esta materia se realizaron durante los años 90 y la primera mitad de la década de los 2000, entre las que destacan la de García, Troiano y Zaldívar (1993), coordinada por Marina Subirats, y la desarrollada por Blanco (Blanco, 2000a). No obstante, se trata de un tema que ha continuado siendo objeto de estudio en los últimos años.

2 Ley Orgánica 2/2006, de 3 de mayo, de Educación, segundo punto de la disposición adicional cuarta. Boletin Oficial del Estado. Estado.

4 Decreto II9/20I5, de 23 de junio, de ordenación de las enseñanzas de la educación primaria, artículo 14. Diario Oficial de la Generalitat de Catalunya.

s Decreto 32/2014 de i8 de julio, por el que se establece el currículo de la educación primaria en las Illes Balears, artículo 24. Boletín Oficial de las Islas Baleares.

6 Decreto ro8/20I4, de 4 de julio, del Consell, por el que establece el currículo y desarrolla la ordenación general de la educación primaria en la Comunitat Valenciana, segundo punto de la disposición adicional tercera. Diario Oficial de la Comunidad Valenciana. 
EL PAPEL DE LAS MUJERES EN LA HISTORIA SEGÚN LAS IMÁGENES DE LOS LIBROS DE TEXTO. COMPARACIÓN DE MANUALES EDITADOS DURANTE LA LOE Y LA LOMCE JUAN CARLOS BEL MARTÍNEZ

Asimismo, podemos establecer una relación entre la concentración de estudios en estos años y la celebración en I995 de la IV Conferencia Mundial sobre Mujeres organizada por Naciones Unidas. En ella se trató de forma extensa este tema y se plantearon una serie de medidas con las que se pretendía eliminar los estereotipos sociales presentes en los programas de estudio, los libros de texto y la enseñanza (Pérez y Gargallo, 2008: 628).

Los motivos por los que esta disciplina ha sido tan ampliamente estudiada los podemos encontrar al observar la situación de las niñas en la escuela a lo largo de los años. Una situación que, desde el establecimiento de la educación mixta en i970, se ha definido legalmente como de igualdad de oportunidades, pero que en realidad supuso la incorporación de las mujeres al sistema educativo androcéntrico, al considerar a este como el modelo pedagógico que debía prevalecer (Subirats, 1994: 66).

\subsection{La transmisión de valores a través de los libros de texto y sus imágenes}

Tal y como se ha señalado previamente, la fuerte influencia que ejercen los libros de texto sobre el currículum oculto es innegable, y su análisis nos puede dar a conocer las concepciones sociales más extendidas. No obstante, hay que tener en cuenta que son diversas las fuentes que intervienen en la adquisición de valores por parte del alumnado además de los manuales. De entre ellas, Ulivieri (2007: 170) y Terrón y Cobano (2008: 387) destacan en primer lugar que la que posee una mayor influencia socializadora es la familia, aunque no debemos olvidar que es en los organismos educativos donde se consolidan todos los estereotipos mediante el uso del lenguaje, la transmisión del saber, los métodos utilizados y todo lo que conlleva el currículum oculto. Por otro lado, no se debe minusvalorar el papel de las organizaciones de educación no formal, ya que los principios pedagógicos escogidos y las prácticas que lleven a cabo a lo largo del tiempo también tendrán una gran influencia en la formación de identidades, como demuestra el caso de los grupos scouts (Bosna y García, 20I2).

Centrándonos en los manuales escolares, la mayoría de autores coinciden en que contienen aquellos saberes que la sociedad considera importantes, por lo que será difícil encontrar en su interior elementos disonantes (Lomas, 2002: 194; Morales y Lischinsky, 2008: I24; Ruiz y Vallejo, I999: 138). Estos saberes se encuentran relacionados con los intereses de las élites de poder, tal y como apunta uno de los mayores exponentes en estudio del currículum oculto, Jurjo Torres (I991: 98): «[...] los recursos didácticos funcionan como filtro de selección de aquellos conocimientos y verdades que coinciden con los intereses de las clases y grupos sociales dominantes».

En este punto tienen un papel evidente las editoriales, ya que justo como advierte Lomas (2002):

Cualquier libro de texto incluye tanto ideas y concepciones sobre la realidad como modos de entender el pasado y el presente de las sociedades, tanto estereotipos culturales como prejuicios sociales y sexistas, en definitiva unas $u$ otras actitudes sobre mujeres y sobre hombres, sobre las clases sociales y sobre los grupos culturales... [...]. (p. 196).

Por lo tanto, son ellas las encargadas de interpretar la ley y decidir los contenidos que se tratarán y los que no (Lomas, 2002: 195), así como la forma en que aparecerán estos según su propia visión del mundo (Bernete, I994: 60). 
Es en dicha selección, condicionada por los criterios que cada una de las editoriales aplica, donde se incrustan los estereotipos dirigidos a los distintos grupos sociales. Estereotipos que, no lo olvidemos, cumplen una función social al crear y mantener la ideología colectiva que establece diferencias y jerarquías en la valoración de unos grupos sobre otros (Blanco, 200ob: I2O).

En el caso de los estereotipos de género, son diversos los autores que han advertido tanto del papel de la acción educativa (Blanco, 200ob; Lomas, 2002; Terrón y Cobano, 2008), como de los manuales escolares (Blanco, 200ob), en la creación de las identidades personales y sociales, así como en la asunción del propio género y los valores sociales. Una construcción que se caracteriza por ser realmente restrictiva al ofrecer modelos de identificación muy limitados o poco realistas (Blanco, 2000a: I72; 200ob: 145 ).

Un buen ejemplo de esta restricción lo podemos encontrar en los resultados de los estudios de Blanco (200ob), Hamodi (20I4), Moreno (1986) y Terrón y Cobano (2008), que demuestran que, en los libros de texto, existe una relación entre el género y los ámbitos de la vida en los que aparecen los personajes. De este modo, las mujeres aparecen siempre en un porcentaje superior en los ámbitos privados, mientras que los hombres lo hacen en los públicos.

A pesar de esto, tanto Blanco (2000a, 200ob) como Terrón y Cobano (2008) apuntan a que la tendencia en los últimos años es de un avance progresivo en la igualdad de género en los manuales, aunque, tal y como coinciden estos autores, dicha mejora es insuficiente. Además, recientemente también se ha percibido que los rasgos androcéntricos en los materiales didácticos siguen apareciendo, aunque cada vez de forma más sutil. Así lo han demostrado en sus respectivos estudios Pérez y Gargallo (2008) y Hamodi (20I4).

Por otra parte, aunque no vamos a entrar a valorar en profundidad si está bien o no utilizar libros de texto como material didáctico debido a que excede los límites específicos de este trabajo, sí queremos señalar los tres tipos de docentes que utilizan este recurso (Martínez, Valls y Pineda, 2009: 7) y que se clasifican de la siguiente forma: en primer lugar, aquellos docentes que hacen un uso exclusivo de ellos y los usan para enseñar conceptos al alumnado; en segundo lugar, los que los utilizan como medio para que alumnas y alumnos apliquen los contenidos, $\mathrm{y}$, finalmente, el grupo que los emplea para propiciar la reflexión crítica. Por otro lado, estaría el profesorado que considera que este recurso es inservible para la educación actual y es partidario de utilizar otros materiales o crear los suyos propios (Sáiz, 20II: 56).

En referencia a la elección de las imágenes como elemento de estudio para esta investigación, a priori cabe señalar que probablemente estas caerán en representar la realidad de forma infantil al ir dirigidas al alumnado de Educación Primaria (Terrón y Cobano, 2008: 393), aunque al pertenecer a manuales de su último curso este rasgo será menos intenso en comparación a manuales de cursos anteriores. Además, la elección de los materiales de sexto tiene un especial interés por el hecho de que esta es una etapa de gran importancia para la creación de las identidades sociales y personales del alumnado (Hamodi, 20I4: 38).

Por otra parte, a la hora de plantear una investigación basada en el análisis de la imagen, debemos tener en cuenta que esta se caracteriza por ser polisémica (Prendes, 1997: 5), por lo que cada individuo podría hacer una interpretación diferente de ella. A pesar de esto, existen una serie de elementos icónicos que transmiten de forma 
EL PAPEL DE LAS MUJERES EN LA HISTORIA SEGÚN LAS IMÁGENES DE LOS LIBROS DE TEXTO. COMPARACIÓN DE MANUALES EDITADOS DURANTE LA LOE Y LA LOMCE JUAN CARLOS BEL MARTÍNEZ

implícita las mismas ideas a la mayoría de sujetos, como es el caso de los componentes sexistas en las ilustraciones.

\subsection{Estudios de género en didáctica de la historia}

Los libros de texto de Historia son un recurso de gran riqueza para el análisis del campo que nos ocupa por el gran número de convenciones sociales que transmiten. De este modo, tal y como apunta Torres (I99I):

La mayoría de investigaciones sobre el contenido de los libros de texto suele concentrarse en el área de ccss porque entre las misiones de esta, se incluyen el posibilitar una comprensión de la sociedad actual, de su génesis y de las posibilidades y los condicionamientos de la realidad presente. El hecho de comprobar como ya en la presentación de información se cometen omisiones y deformaciones nos lleva a pensar que esos objetivos difícilmente pueden ser alcanzados (p. I03).

Con esta afirmación coinciden diversos autores, como Blanco (2000a: 83) y Pérez y Gargallo (2008: 630), al señalar que en los manuales de Ciencias Sociales la discriminación hacia las mujeres es mayor que en otras áreas del currículum. Esto se encuentra estrechamente relacionado con la imposición de una mirada exclusivamente masculina de la Historia (Martín, 2006), así como con la omisión de la aportación de las mujeres al desarrollo de la humanidad (Blanco, 2000a, 200ob; Lomas, 2002; Subirats, 1994; Vega, 2002).

En cuanto a la progresión que han seguido en nuestro país las investigaciones sobre este tema, cabe destacar en primer lugar la realizada por Amparo Moreno (I986) sobre los manuales de Historia de Bup. Este estudio pionero demostró, por medio del análisis del discurso histórico, la forma en que las mujeres eran discriminadas en los libros de texto de Historia no sólo por su escasa presencia, sino también por el trato preferente que recibían las actuaciones públicas (protagonizadas por los hombres) con respecto a las privadas (protagonizadas por las mujeres).

Al mismo tiempo, dicha autora definió el modelo hegemónico de identificación que presentaban estos materiales para ambos sexos. Este era el de un hombre adulto de raza blanca, miembro de la cristiandad europea occidental y que estaba dotado de poderes y saberes que le permitían expandirse territorialmente sobre otros con el fin de imponer su civilización universal.

En su estudio sobre los libros de texto de EGB, Garreta y Careaga (1987) detectaron que en el área de Ciencias Sociales la presencia y el protagonismo de las mujeres en las ilustraciones estaba muy por debajo de la de los hombres, además de advertir sobre un hecho notorio en los manuales de Historia: de entre las pocas mujeres que aparecían como protagonistas de las imágenes, una proporción destacada lo hacía por su relación con otros hombres.

Uno de los estudios más trascendentales en este campo fue el coordinado por Marina Subirats (García et al., 1993). Analizando diversos elementos de los libros de Ciencias Sociales, como los textos, las ilustraciones o las actividades, el estudio consiguió determinar cómo se manifestaba el sexismo por medio de ellos, así como definir una serie de indicadores para detectarlo en los manuales didácticos. 

JUAN CARLOS BEL MARTÍNEZ

En su análisis del discurso probó que la ya limitada presencia tanto de los personajes femeninos como de las mujeres con nombre propio había disminuido todavía más en comparación a estudios previos; además de indicar que aquellas que destacaron en la Historia lo hicieron por continuar las tareas que habían iniciado los varones o por poseer atributos tradicionalmente propios del género masculino. A unas conclusiones muy similares se llegó examinando las ilustraciones, donde destacó que la presencia de mujeres era mayor en comparación al texto, a pesar de seguir teniendo una representación reducida.

Otro estudio de relevancia en este ámbito fue el de Nieves Blanco (2000a), donde esta autora se centró en estudiar los elementos del discurso en diversas asignaturas, así como sus ilustraciones. En los libros de texto de Ciencias Sociales llegó a unos resultados semejantes con respecto a estudios anteriores, aunque sí destacó cierta mejoría en todos los campos con respecto al tratamiento y la aparición de las mujeres. A pesar de esto, los índices de presencia femenina continuaron siendo muy bajos con respecto a la masculina en todos los niveles, tanto en la presencia individual, como en la colectiva y en la identificable (con nombre propio). Al mismo tiempo, las mujeres seguían estando especialmente vinculadas al ámbito doméstico y a planos alejados de la realidad, al ser los modelos de identificación más frecuentes los de diosas o vírgenes.

Más recientemente, López-Navajas (20I4) presentaba un análisis de los manuales de tres editoriales de todas las asignaturas de la EsO, en el que probaba que en los libros de Ciencias Sociales la discriminación de las mujeres continuaba siendo superior con respecto al resto de áreas del currículum. No obstante, sí percibía una leve mejoría en la presencia de estas en comparación con el estudio de Blanco (2000a), mejoría que era manifiestamente insuficiente teniendo en cuenta que había pasado más de una década desde la realización de este último estudio.

\section{Metodología}

\section{I. Objetivos}

En este trabajo se pretende analizar la presencia y el papel de las mujeres que aparecen (o bien están ausentes) en las imágenes de los libros de texto de Historia para comprobar si dichas imágenes transmiten de una forma androcéntrica la enseñanza de la historia de la Humanidad. A partir de ello se intenta plantear una reflexión necesaria sobre los manuales educativos así como ofrecer criterios que faciliten un análisis similar de otros materiales didácticos, como los utilizados en el Aprendizaje Basado en Proyectos (ABP). Al mismo tiempo, se compararán los resultados obtenidos entre manuales de las dos últimas reformas educativas: LOE y LOMCE.

\subsection{Muestra}

Esta investigación toma como materiales de análisis de 4 libros de texto de sexto curso de Educación Primaria de 2 de las editoriales con mayor difusión en la Comunidad Valenciana (Santillana y Vicens Vives). De estos, 2 fueron publicados en 201 bajo 
EL PAPEL DE LAS MUJERES EN LA HISTORIA SEGÚN LAS IMÁGENES DE LOS LIBROS DE TEXTO. COMPARACIÓN DE MANUALES EDITADOS DURANTE LA LOE Y LA LOMCE JUAN CARLOS BEL MARTÍNEZ

la Ley Orgánica de Educación (LOE) y 2 en 2015 a partir de la Ley Orgánica para la Mejora de la Calidad Educativa (LOMCE).

Al ser la Historia la disciplina estudiada, los libros seleccionados han sido los de Conocimiento del Medio para aquellos editados durante la LOE y los de Ciencias Sociales para los publicados bajo la LOMCE, acotando el estudio únicamente a las unidades relativas a temas históricos.

Tomando como elemento central a los personajes de las imágenes, se han descartado aquellas en las que no aparece ningún personaje, así como las que, por sus características o diseño, impiden identificar el sexo de los sujetos. De este modo, se han encontrado diversos tipos de imágenes en los que se puede reconocer el sexo de los personajes: dibujos, fotografías, pinturas, fotogramas de películas, siluetas, etc.; por lo tanto, se han valorado tanto imágenes creadas por los ilustradores de las editoriales como imágenes de fuentes externas.

\subsection{Instrumento de estudio}

A la hora de escoger los criterios con los que analizar estas imágenes se han tenido en cuenta los métodos utilizados por autores recientes como Terrón y Cobano (2008) y Hamodi (20I4), así como los de otros más clásicos como los propuestos por Blanco (2000a), y especialmente el sistema de indicadores para reconocer el sexismo en las ilustraciones de los libros de texto de Ciencias Sociales, formulado por el equipo coordinado por Marina Subirats (García et al., I993). A pesar de esto, algunos de los criterios tomados como referencia han sido modificados para adaptarlos al presente estudio.

En primer lugar, con el fin de valorar la presencia que tiene cada tipo de personaje en los materiales estudiados, se ha contabilizado el número de apariciones de cada uno (Frecuencia de aparición de personajes), reformulando algunas de las categorías propuestas por García et al. (I993). Así se han considerado las siguientes para cada imagen: Mujeres (una o dos mujeres), Colectivo de mujeres (más de dos mujeres o un conjunto mixto con mayoría de mujeres), Varones (uno o dos varones), Colectivo de varones (más de dos varones o un conjunto mixto con mayoría de varones), Colectivo mixto igualado (más de dos personajes de diferente sexo con una diferencia entre ambos grupos menor al IO-I5\% de la mitad del total), Parejas mixtas (una mujer y un varón) y Personajes asexuados (aquellos cuya identificación no es evidente, como es el caso de los bebés u otros personajes representados de forma ambigua en relación a su sexo).

Por otro lado, para evidenciar el reconocimiento social que se da a personajes concretos en función de su sexo (Personajes con nombre propio) se han seleccionado las categorías siguientes de entre las propuestas por García et al. (1993) y Blanco (2000a): Mujeres con nombre propio, Colectivo de mujeres con nombre propio, Varones con nombre propio y Colectivo de varones con nombre propio. En esta sección del estudio se han tenido en cuenta los pies de imagen y los rótulos que acompañan a estas con el fin de identificar a cada sujeto.

Con el propósito de conocer los roles y funciones que desempeñan los individuos representados dependiendo de su género (Roles y funciones de los personajes), se han adaptado los criterios formulados por García et al. (1993) y se han aplicado los siguientes a los protagonistas de cada imagen: Mujeres en roles activos, Mujeres en 

JUAN CARLOS BEL MARTÍNEZ

roles pasivos, Varones en roles activos, Varones en roles pasivos. En este caso, también se ha incluido en cada grupo de «Roles pasivos» a aquellos sujetos que estaban posando en la imagen, y se han descartado aquellas imágenes en las que el protagonismo reflejado en ellas era ambiguo o compartido entre más de un personaje.

Finalmente, para reconocer el contexto al que está vinculado cada personaje en función de su sexo (Entorno que rodea a los personajes) se han adaptado las categorías utilizadas por Terrón y Cobano (2008), distinguiendo en función del sexo: Mujeres en lugares públicos, Mujeres en lugares privados, Varones en lugares públicos y Varones en lugares privados. Evidentemente, en esta parte del análisis se ha prescindido de las representaciones de personajes que carecían de entorno.

\section{Resultados}

A continuación pasamos a mostrar y comentar los resultados obtenidos en el presente estudio ${ }^{7}$. Estos se expondrán en forma de tabla y se indicará tanto la frecuencia de aparición (F) como la proporción (\%) de dicha frecuencia en relación a los manuales de que se trate.

\begin{tabular}{|c|c|c|c|c|c|c|c|c|c|c|c|c|}
\hline & \multicolumn{6}{|c|}{ LOE } & \multicolumn{6}{|c|}{ LOMCE } \\
\hline & \multicolumn{2}{|c|}{ Santillana } & \multicolumn{2}{|c|}{ V. Vives } & \multicolumn{2}{|c|}{ TOTAL } & \multicolumn{2}{|c|}{ Santillana } & \multicolumn{2}{|c|}{ V. Vives } & \multicolumn{2}{|c|}{ TOTAL } \\
\hline & $\mathrm{F}$ & $\%$ & $\mathrm{~F}$ & $\%$ & $\mathrm{~F}$ & $\%$ & $\mathrm{~F}$ & $\%$ & $\mathrm{~F}$ & $\%$ & $\mathrm{~F}$ & $\%$ \\
\hline $\mathrm{M}$ & 2 & 3,4 & $\mathrm{I3}$ & 8,9 & 15 & 7,2 & II & $\mathrm{I} 7,4$ & 16 & $\mathrm{I} 2,2$ & 27 & 13,9 \\
\hline $\mathrm{CM}$ & 5 & 8,6 & 16 & 10,9 & $2 \mathrm{I}$ & $\mathrm{IO}, 2$ & 7 & $\mathrm{II}, \mathrm{I}$ & II & 8,4 & 18 & 9,2 \\
\hline V & $\mathrm{I} 4$ & $24, \mathrm{I}$ & 64 & 43,8 & 78 & 38 & I4 & 22,2 & 49 & 37,4 & 63 & 32,4 \\
\hline $\mathrm{CV}$ & 29 & 50 & 34 & 23,3 & 63 & 31,7 & $2 \mathrm{I}$ & 33,3 & $4 \mathrm{I}$ & $3 \mathrm{I}, 3$ & 62 & 31,9 \\
\hline MIX & 6 & $\mathrm{IO}, 3$ & 6 & $4, \mathrm{I}$ & $\mathrm{I} 2$ & 5,8 & 3 & 4,7 & 8 & $6, \mathrm{I}$ & II & 5,6 \\
\hline PM & I & $\mathrm{I}, 7$ & 9 & $6, \mathrm{I}$ & IO & 4,8 & 5 & 7,9 & 5 & 3,8 & IO & $5, \mathrm{I}$ \\
\hline PA & I & $\mathrm{I}, 7$ & 4 & 2,7 & 5 & 2,3 & 2 & 3,1 & I & 0,7 & 3 & $\mathrm{I}, 5$ \\
\hline TI & 58 & 100 & 146 & 100 & 204 & 100 & 63 & 100 & I3I & 100 & 194 & 100 \\
\hline
\end{tabular}

$M=$ mujeres, $C M=$ colectivo de mujeres, $V=$ varones, $C V=$ colectivo de varones, $M I X=$ colectivo mixto igualado, $P M=$ parejas mixtas, $P A=$ personajes asexuados, $T I=$ total de imágenes analizadas.

Tabla r: Frecuencia de aparición de personajes.

Empezando por valorar la frecuencia con la que aparece cada tipo de personaje o grupo de personajes (Tabla I), podemos observar cómo, en términos generales, los varones y los colectivos de varones son los agentes más representados, mientras que las mujeres y sus colectivos aparecen en una escasa proporción. Debemos hacer especial mención al caso del manual de Santillana editado durante la LOE, en el que el índice de mujeres es del 3,4\%. Además, los colectivos mixtos igualados, así como las parejas y los personajes asexuados, tienen una presencia ínfima en todos los casos.

Conviene advertir que hemos decidido realizar las valoraciones considerando las editoriales individualmente y también comparándolas entre sí, sin entrar a valorar los resultados totales ya que los dos ejemplares de V. Vives tienen un peso tan fuerte que introducen un sesgo en los datos totales. 
En cuanto al progreso que han seguido estas dos editoriales, distinguimos una importante evolución en la presencia de mujeres en el manual de Santillana, aumentando del $3,4 \%$ al $17,4 \%$. También percibimos en dicha editorial una reducción drástica del número de colectivos de varones (del $50 \%$ al $33,3 \%$ ) y de colectivos mixtos igualados (del Io,3\% al 4,7\%). En cuanto a V. Vives, aumentan las imágenes de mujeres (del $8,9 \%$ al I2,2\%) y de colectivos de varones (del $23,3 \%$ al $31,3 \%$ ), aunque se reducen las de colectivos de mujeres (del Io,9\% al 8,4\%) y las de varones (del $43,8 \%$ al $37,4 \%$ ).

\begin{tabular}{|c|c|c|c|c|c|c|c|c|c|c|c|c|}
\hline & \multicolumn{6}{|c|}{ LOE } & \multicolumn{6}{|c|}{ LOMCE } \\
\hline & \multicolumn{2}{|c|}{ Santillana } & \multicolumn{2}{|c|}{ V. Vives } & \multicolumn{2}{|c|}{ TOTAL } & \multicolumn{2}{|c|}{ Santillana } & \multicolumn{2}{|c|}{ V. Vives } & \multicolumn{2}{|c|}{ TOTAL } \\
\hline & $\mathrm{F}$ & $\%$ & $\mathrm{~F}$ & $\%$ & $\mathrm{~F}$ & $\%$ & $\mathrm{~F}$ & $\%$ & $\mathrm{~F}$ & $\%$ & $\mathrm{~F}$ & $\%$ \\
\hline$M$ & I & $4, \mathrm{I}$ & IO & 16,9 & II & 13,3 & I & 5,2 & 6 & 17,6 & 7 & I2 \\
\hline CM & o & $\mathrm{o}$ & I & $\mathrm{I}, 7$ & I & $\mathrm{I}, 2$ & $\mathrm{o}$ & o & 2 & 2,4 & 2 & 3,9 \\
\hline $\mathrm{V}$ & 22 & $9 \mathrm{I}, 6$ & 44 & 74,5 & 66 & 79,5 & 17 & 89,4 & 25 & 73,6 & 42 & 75 \\
\hline $\mathrm{CV}$ & I & $4, \mathrm{I}$ & 4 & 6,7 & 5 & 6 & I & 5,2 & 4 & 6,4 & 5 & 8,9 \\
\hline TI & 24 & 100 & 59 & IOO & 83 & 100 & I9 & 100 & 37 & 100 & 56 & 100 \\
\hline
\end{tabular}

$M=$ mujeres con nombre propio, $C M=$ colectivo de mujeres con nombre propio, v=varones con nombre propio, $C V=$ colectivo de varones con nombre propio, $T I=$ total de imágenes analizadas.

Tabla 2: Personajes con nombre propio.

En cuanto a la identificación de los personajes, la Tabla 2 muestra el número y la proporción de protagonistas con nombre propio de las imágenes de estos manuales. Aquello que primero llama nuestra atención es la hegemonía que reflejan las cifras referentes a varones concretos respecto al resto de personajes, que en ningún caso es inferior al $70 \%$.

Comparando los resultados obtenidos en los libros de cada editorial, podemos ver cómo el número de mujeres con nombre propio en las ilustraciones de Santillana sigue siendo el mismo, y en las de $\mathrm{V}$. Vives se ha reducido algunas décimas, con lo que casi no se producen cambios. Por otro lado, en los nuevos tomos se ha reducido el número de varones identificados, pasando en el caso de Santillana del 91,6\% al 89,4\%, y en el de V. Vives del 74,5\% al 67,5\%. También hay que decir que ha aumentado la proporción de colectivos de varones en ambos casos, a pesar de presentar la misma frecuencia.

\begin{tabular}{|c|c|c|c|c|c|c|c|c|c|c|c|c|}
\hline & \multicolumn{6}{|c|}{ LOE } & \multicolumn{6}{|c|}{ LOMCE } \\
\hline & \multicolumn{2}{|c|}{ Santillana } & \multicolumn{2}{|c|}{ V. Vives } & \multicolumn{2}{|c|}{ TOTAL } & \multicolumn{2}{|c|}{ Santillana } & \multicolumn{2}{|c|}{ V. Vives } & \multicolumn{2}{|c|}{ TOTAL } \\
\hline & $\mathrm{F}$ & $\%$ & $\mathrm{~F}$ & $\%$ & $\mathrm{~F}$ & $\%$ & $\mathrm{~F}$ & $\%$ & $\mathrm{~F}$ & $\%$ & $\mathrm{~F}$ & $\%$ \\
\hline MA & 3 & 5,2 & 22 & $\mathrm{I} 6,5$ & 25 & $\mathrm{I} 3,2$ & 8 & $\mathrm{I} 4,5$ & 20 & 15,8 & 28 & 15,4 \\
\hline MP & 8 & 14 & 18 & 13,5 & 26 & 13,7 & 9 & 16,3 & $\mathrm{I} 2$ & 9,5 & $2 \mathrm{I}$ & $\mathrm{II}, 6$ \\
\hline VA & 32 & $56, \mathrm{I}$ & 42 & $3 \mathrm{I}, 6$ & 74 & 38,9 & 20 & 36,3 & 58 & $46, \mathrm{I}$ & 78 & $43, I$ \\
\hline $\mathrm{VP}$ & I4 & 24,7 & $5 \mathrm{I}$ & 38,4 & 65 & 34,2 & 18 & 32,7 & 36 & 28,6 & 54 & 29,9 \\
\hline TI & 57 & 100 & $\mathrm{I} 33$ & 100 & 190 & 100 & 55 & 100 & 126 & 100 & I8I & 100 \\
\hline
\end{tabular}

$M A=$ mujeres en roles activos, $M P=$ mujeres en roles pasivos, $V A=v a r o n e s$ en roles activos, $V P=v a r o n e s$ en roles pasivos, $T I=$ total de imágenes analizadas.

Tabla 3: Roles y funciones de los personajes. 

JUAN CARLOS BEL MARTÍNEZ

En referencia a la actividad o pasividad de los personajes protagonistas de las imágenes en función de su sexo (Tabla 3), lo primero en lo que reparamos es que los varones, tanto activos como pasivos, ocupan una posición central en la mayoría de imágenes; hecho estrechamente relacionado con su presencia dominante.

De este modo, comparando los resultados obtenidos entre ejemplares de diferentes leyes educativas, podemos ver cómo en el de Santillana ha aumentado en 9 puntos la proporción de mujeres activas y se ha reducido de forma contundente la de varones activos (del 56,1\% al 36,3\%). En cuanto a V. Vives, ha disminuido tanto la proporción de mujeres activas como de pasivas y ha aumentado considerablemente la de varones activos, concretamente del 31,6\% al 46,I \%.

\begin{tabular}{|c|c|c|c|c|c|c|c|c|c|c|c|c|}
\hline & \multicolumn{6}{|c|}{ LOE } & \multicolumn{6}{|c|}{ LOMCE } \\
\hline & \multicolumn{2}{|c|}{ Santillana } & \multicolumn{2}{|c|}{ V. Vives } & \multicolumn{2}{|c|}{ TOTAL } & \multicolumn{2}{|c|}{ Santillana } & \multicolumn{2}{|c|}{ V. Vives } & \multicolumn{2}{|c|}{ TOTAL } \\
\hline & $\mathrm{F}$ & $\%$ & $\mathrm{~F}$ & $\%$ & $\mathrm{~F}$ & $\%$ & $\mathrm{~F}$ & $\%$ & $\mathrm{~F}$ & $\%$ & $\mathrm{~F}$ & $\%$ \\
\hline MU & 6 & $\mathrm{I} 2,2$ & 13 & 14,9 & 19 & $\mathrm{I} 4$ & I4 & $29, \mathrm{I}$ & 16 & $\mathrm{I} 6,6$ & 30 & 20,8 \\
\hline MV & 3 & $6, \mathrm{I}$ & $\mathrm{I} 4$ & $16, \mathrm{I}$ & I7 & $\mathrm{I} 2,5$ & 5 & $\mathrm{IO}, 4$ & $\mathrm{I} 4$ & 14,6 & 19 & $\mathrm{I} 3,2$ \\
\hline $\mathrm{VU}$ & 34 & 69,5 & 54 & 62,1 & 88 & 64,7 & 25 & 52,2 & 52 & 54,2 & 77 & 53,5 \\
\hline VV & 6 & $\mathrm{I} 2,2$ & 6 & 6,9 & I2 & 8,8 & 4 & 8,3 & $\mathrm{I} 4$ & $\mathrm{I4}, 6$ & I8 & $\mathrm{I} 2,5$ \\
\hline TI & 49 & 100 & 87 & 100 & 136 & 100 & 48 & 100 & 96 & 100 & $\mathrm{I} 44$ & 100 \\
\hline
\end{tabular}

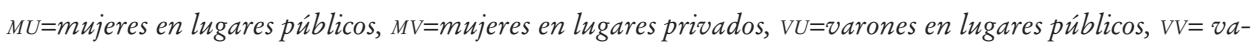
rones en lugares privados, $T I=$ total de imágenes analizadas.

Tabla 4: Entorno que rodea a los personajes.

Finalmente, la Tabla 4 muestra los datos relativos al entorno (público o privado) en el que se encuentran los personajes protagonistas. A partir de esta información podemos ver cómo la presencia de varones en lugares públicos es muy superior al resto de variantes, destacando especialmente las amplias diferencias de los índices de varones entre los dos ámbitos; por el contrario, en el caso de las mujeres estos datos presentan un mayor equilibrio entre las dos categorías.

Al contrastar los resultados obtenidos en materiales de diferentes reformas educativas vemos que tanto en Santillana cómo en V. Vives aumenta la proporción de mujeres en lugares públicos, pero a pesar de reducirse el número de varones en estos ambientes, su predominio sobre las mujeres continua siendo abrumador.

\section{Conclusiones}

Pasando a comentar las conclusiones a las que se ha llegado, podemos observar cómo la presencia de mujeres en las imágenes continúa siendo muy inferior a la de hombres, tal y como demostraron investigaciones previas (Blanco, 200oa; García et al., 1993; Garreta y Careaga, 1987; López-Navajas, 2014; Terrón y Cobano, 2008). A pesar de ello su frecuencia de aparición ha aumentado ligeramente respecto a estos estudios anteriores, confirmando así la tendencia identificada en los trabajos más recientes (López-Navajas, 20I4; Terrón y Cobano, 2008).

Una representación tan escasa, tanto de las mujeres como de los colectivos de mujeres, muestra hasta qué punto son marginadas del discurso histórico en los manuales, 
EL PAPEL DE LAS MUJERES EN LA HISTORIA SEGÚN LAS IMÁGENES DE LOS LIBROS DE TEXTO. COMPARACIÓN DE MANUALES EDITADOS DURANTE LA LOE Y LA LOMCE JUAN CARLOS BEL MARTÍNEZ

ya que habitualmente las imágenes no dejan de ser un reflejo de aquello que expone el texto -el cual es valorado como la principal fuente histórica-, al ser consideradas por gran parte de las editoriales más como un elemento decorativo que como un documento histórico (Valls, 2007b: 12). Además, la ocultación de las mujeres evidencia la forma en que desde la escuela se imponen los valores tradicionalmente masculinos y se silencia la cultura femenina (Blanco, 2000a: 83; Ulivieri, 2007: 173) al impedirle concurrir en la cultura colectiva.

A pesar de aumentar levemente la presencia de mujeres, el protagonismo histórico y social lo siguen ostentando los hombres; buena prueba de ello es que en nuestro estudio prácticamente 7 de cada io personajes reconocidos individualmente por sus aportaciones son hombres. A unas conclusiones similares llegaron Blanco (2000a) y García et al. (1993), aunque hay que reconocer que en este sentido también se percibe un ligero aumento de la presencia de mujeres con nombre propio en comparación a dichos trabajos.

Una representación tan sesgada de la Historia y de la contribución de las mujeres al desarrollo de la Humanidad demuestra aquello que ya apuntaban García et al. (1993: 66): son los varones adultos que ostentan el poder (político, económico, militar, etc.) los protagonistas exclusivos de la Historia, y tan sólo aquellas mujeres que se adecuan a ese arquetipo viril de poder son reconocidas; buen ejemplo de ello son los retratos de Isabel II analizados en este trabajo. Por este motivo podemos afirmar que, tal y como señalan Blanco (2000a: 77) y Vega (2002: I6), la Historia que se enseña mediante los manuales escolares es la historia del poder político y económico, y mientras se sigan teniendo únicamente en cuenta estas categorías no se reconocerá la aportación de las mujeres al haber sido excluidas de estos ámbitos durante miles de años.

Del mismo modo se ha percibido cómo una importante proporción de las mujeres que aparecían o eran destacadas, lo hacían por su relación -familiar o personal- con varones ilustres, al igual que evidenciaron García et al. (1993: 94) y Garreta y Careaga (1987: 155) en sus estudios.

En cuanto a los roles que muestran los personajes, llama la atención cómo, mientras que las mujeres que realizan alguna función y las que se encuentran en actitud pasiva presentan porcentajes similares, los varones aparecen en la gran mayoría de casos llevando a cabo alguna actividad. Esta situación denota una forma engañosa de mostrar los trabajos y ocupaciones que han desempeñado las mujeres a lo largo de los años. Queremos llamar la atención sobre el caso de los dibujos empleados por la editorial Vicens Vives para ilustrar a las mujeres en el ámbito laboral, en los que aparecen en las fábricas textiles del s. XIX siendo siempre observadas y supervisadas por hombres que se encuentran en puestos de mando. Por el contrario, Santillana se caracteriza por una mayor diversidad de este tipo de imágenes, al aparecer en ellas las mujeres a solas sin mostrar la jerarquía existente. Sin entrar a valorar cuál de estas dos formas de representación es la más adecuada, conviene destacar que las primeras deberían acompañarse de actividades de reflexión para el aula sobre esta desigualdad de género en el pasado, puesto que de no ser así el alumnado podría interpretar en clave androcéntrica el mensaje transmitido; por otro lado, al mostrar las segundas la realidad de forma parcial y no reparar en la condición de subordinación que sufrían las mujeres, estarían impidiendo la reflexión sobre estas situaciones.

Un aspecto que también ofrece mucha información sobre la importancia social que tienen los personajes es el entorno en que aparecen representados. Investigaciones 
como la de Blanco (200ob) o la de Terrón y Cobano (2008) demostraron que las mujeres aparecían en la mayoría de imágenes en lugares privados mientras que los hombres lo hacían en los públicos. Nuestro estudio demuestra que esta situación ha cambiado en los manuales actuales, aunque sucede algo similar a lo comentado sobre los roles de los personajes: las mujeres se encuentran de forma equilibrada en los dos ambientes mientras que la representación de los hombres es mucho mayor en las esferas públicas que en las privadas. En gran medida esta situación continúa siendo heredera del fuerte arraigo que tuvo en el siglo xix el modelo liberal-burgués y católico en España (Ballarín, 2007: I49), que confinaría a las mujeres al espacio doméstico justificándolo como un bien social y moral.

Evidentemente, una mayor influencia en el ámbito público supone una mejor valoración a nivel social ya que es en este entorno donde se ejerce el poder a nivel colectivo. Además de esta valoración, hay que tener en cuenta la consideración general de que las actividades desarrolladas en entornos públicos requieren de más conocimientos (Terrón y Cobano, 2008: 394), por lo que al existir una disparidad tan grande de los varones entre las dos esferas se está legitimando nuevamente su posición como únicos protagonistas de la Historia, sin incorporar un relato igualitario que incluya a las mujeres.

Dicho relato podría plantear el estudio de otras áreas de gran importancia para el conocimiento del pasado de la vida colectiva, dándole así a la Didáctica de la Historia un carácter más social y planteando, por ejemplo, la historia de la vida cotidiana (Valls, 2007a: 216), de las formas del trabajo, de las formas de obtención de los alimentos o la del uso y obtención de la energía (Valls, 2007b: I8).

Observando ahora los resultados de forma global y habiendo interpretado la información que nos transmiten, podemos contestar afirmativamente a la cuestión que planteábamos al inicio del presente trabajo: los libros de texto muestran por medio de sus ilustraciones un relato androcéntrico de la historia de la Humanidad.

A pesar de que reconocemos cierta mejora en la mayoría de criterios de estudio que hemos planteado, consideramos insuficiente dicha evolución, y hay que señalar que este progreso no parece un efecto de la aplicación de la LOMCE ya que, como hemos apuntado al inicio del estudio, esta ley no reconoce en ningún punto la importancia de la igualdad de género en los manuales.

Con el fin de mejorar la situación que hemos descrito, consideramos de gran importancia concienciar a todos los agentes educativos al respecto. Una reflexión de este tipo debería corresponder especialmente al profesorado, ya que es él el que tiene el papel más determinante en este sentido y sus actuaciones podrían ir dirigidas a un uso más responsable de las imágenes como material didáctico. Con ello favorecerían en el alumnado el análisis crítico y la reflexión sobre las convenciones sociales que muestran las imágenes; incluso, como propone Casablancas (200I: 17), se podría plantear la propia creación de representaciones gráficas a partir del texto con el fin de que el alumnado desarrolle su criterio de análisis particular.

Teniendo en cuenta estas consideraciones, podemos concluir que la concienciación de los agentes educativos (profesorado, editoriales, administración, etc.) es necesaria para transmitir un reflejo mucho más fiel, libre de prejuicios etnocéntricos, del papel de las mujeres a lo largo de la Historia, paso indispensable para alcanzar una verdadera coeducación. 


\section{Bibliografía}

\section{Listado de manuales analizados}

EDITORIAL SANTILLANA:

Etxebarria, L.; Medina, J. I. y Moral, A. (20iI) Coneixement del medi, 6 Primària (Proyecto La Casa del Saber). Valencia: Voramar-Santillana.

vv. AA. (2015) Ciències Socials 6 Primària (Projecte Saber Fer). Valencia: Voramar-Santillana.

Editorial Vicens Vives:

Casajuana, R.; Cruells, E.; García, M.; Gatell, C. y Martínez, M. ${ }^{a}$ J. (2oiI) Medi 6. Medi Natural, Social y Cultural (Proyecto Món de Colors). Madrid: Vicens Vives.

García, M.; Gatell, C. y Batet M. (2015) Socials 6. Comunitat Valenciana (Proyecto Aula Activa). Valencia: Vicens Vives.

\section{Referencias bibliográficas}

Ballarín, P. (2007) La escuela de niñas en el siglo xix: la legitimación de la sociedad de esferas separadas. Historia de la Educación. Revista Interuniversitaria, 26, I43-168.

Bernete, F. (1994) Cómo analizar las representaciones sociales contenidas en los libros de texto de Historia. CL E E: Comunicación, Lenguaje y Educación, 22, 59-74.

Blanco, N. (2000a) El sexismo en los materiales educativos de la ESO. Sevilla: Instituto Andaluz de la Mujer.

Blanco, N. (20oob) Mujeres y hombres para el siglo xxi: El sexismo en los libros de texto. En M. Á. SANTOS GUERRA (coord.) El Harén pedagógico: perspectiva de género en la organización escolar (pp. II9-I47). Barcelona: Graó.

Bosna, V. V. A. y García, M. L. (20I2) Las Exploradoras en Italia, cien años de historia educativa (1912-2012). Aula: Revista de Pedagogía de la Universidad de Salamanca, I8, I55-180.

Casablancas, S. (200I) En cuanto a las imágenes en textos escolares. Recuperado el 28 de agosto, 20I5, de: http://www.silvinacasablancas.com/publicaciones/las_imagenes_en_textos_escolares_Silvina_Casablancas.pdf.

Choppin, A. (2000) Los manuales escolares de ayer a hoy: el ejemplo de Francia. Historia de la Educación. Revista Interuniversitaria, 19, I3-37.

Decret I08/20I4, de 4 de juliol, del Consell, pel qual establix el currículum i desplega l'ordenació general de l'Educació Primària a la Comunitat Valenciana, DOcv 73II \$ 6347 (2014).

Decreto 32/20I4, de 18 de julio, por el que se establece el currículo de la educación primaria en las Illes Balears. BOIB 97 \I3133 (20I4).

Decreto II $/ 2015$, de 23 de junio, de ordenación de las enseñanzas de la educación primaria. DOGC $6900 \ 15176019(2015)$.

García, M.; Troiano, H.; Zaldívar, M. y Subirats, M. (coords.) (1993) El sexismo en los libros de texto: análisis y propuesta de un sistema de indicadores. Madrid: Publicaciones del Instituto de la Mujer, n. ${ }^{\circ}$ 37, Estudios.

Garreta, N. y Careaga, P. (1987) Modelos masculino y femenino en los textos de EGB. Madrid: Publicaciones del Instituto de la Mujer, n. ${ }^{\circ}$ i4, Estudios.

Hamodi, C. (20I4) ¿'Transmiten los libros de texto el valor de la igualdad desde la perspectiva de género? Estudio del lenguaje icónico de dos editoriales. REIRE: Revista D'Innovació $i$ Recerca en Educació, 7 (I), 30-55.

Ley Orgánica 2/2006, de 3 de mayo, de Educación. $B O E$ Io6 $\$ 7899$ (2006).

Ley Orgánica 8/20I3, de 9 de diciembre, para la mejora de la calidad educativa. BOE 295 \I2886 (2013).

Lomas, C. (2002) El sexismo en los libros de texto. En A. González y C. Lomas (coords.) Mujer y educación: educar para la igualdad, educar desde la diferencia (pp. 193-209). Barcelona: Graó. 

JUAN CARLOS BEL MARTÍNEZ

López-Navajas, A. (20I4) Análisis de la ausencia de las mujeres en los manuales de la Eso: una genealogía de conocimiento ocultada. Revista de Educación, 363, 282-308.

Martín, R. (2006) El sexismo en los contenidos de los libros de texto. En M. NúÑ̃z (coord.) Educación y Mujeres II (pp. 75-95). Sevilla: Arcibel.

Martínez, N.; Valls, R. y Pineda, F. (2009) El uso del libro de texto de Historia de España en Bachillerato: diez años de estudio, 1993-2003, y dos reformas (LGE-LOGSE). Didáctica de las Ciencias Experimentales y Sociales, 23, 3-35.

Morales, O. A. y Lischinsky, A. (2008) Discriminación a través de las ilustraciones de libros de texto de Educación Secundaria Obligatoria en España. Discurso E Sociedad, 2 (I), II5-I52.

Moreno, A. (1986) El Arquetipo Viril protagonista de la historia. Barcelona: LaSal. Edicions de les dones.

Pérez, C. y Gargallo, B. (2008) Sexismo y estereotipos de género en los textos escolares. En Actas XXVI Seminario interuniversitario de teoría de la educación: Lectura y educación (pp. 627-636).

Prendes, M. P. (1997) Análisis de imágenes en textos escolares: descripción y evaluación. Recuperado el Io de agosto, 20I5, de http://www.lmi.ub.es/te/any97/prendes_sp/.

Ruiz, L. y Vallejo, C. (1999) ¿Qué queda del sexismo en los libros de texto? Revista Complutense de Educación, io (2), I25-I45.

Sáiz, J. (20II) Actividades de libros de texto de Historia, competencias básicas y destrezas cognitivas, una difícil relación: análisis de manuales de r. ${ }^{\circ}$ y 2..$^{\circ}$ de eso. Didáctica de las Ciencias Experimentales y Sociales, 25, 37-64.

Subirats, M. (1994) Conquistar la igualdad: la coeducación hoy. Revista Iberoamericana de Educación, 6, 49-78.

Terrón, M. T. y Cobano, V. (2008) El papel de la mujer en las ilustraciones de los libros de texto de educación primaria. Foro de Educación, io, 385-400.

Tiana, A. (2000) El Proyecto MANEs y la investigación histórica sobre los manuales escolares (siglos XIX y XX). Historia de la Educación. Revista Interuniversitaria, 19, 179-194.

Torres, J. (199I) El Currículum oculto (2. ${ }^{a}$ ed.). Madrid: Editorial Morata.

Ulivieri, S. (2007) I silenzi e le parole delle donne. Historia de la Educación. Revista Interuniversitaria, 26, 169-180.

VALLs, R. (2007a) Historiografía escolar española: siglos XIX-XXI. Madrid: Universidad Nacional de Educación a Distancia.

VALLS, R. (2007b) Las imágenes en los manuales escolares de Historia y las dificultades de su uso didáctico. Clio E Asociados: La Historia Enseñada, II, II-23.

VegA, C. (2002) La mujer en la historia y la historia de las mujeres. En A. González y C. Lomas (coords.) Mujer y educación: educar para la igualdad, educar desde la diferencia (pp. 13-20). Barcelona: Graó. 